\title{
PARA ONDE ESTÃO INDO AS INVESTIGAÇÕES SOBRE ENSINO DE GEOGRAFIA NO BRASIL? UM OLHAR SOBRE ELEMENTOS DA PESQUISA E DO LUGAR QUE ELA OCUPA NESSE CAMPO
}

\author{
WHERE IS RESEARCH ON GEOGRAPHY TEACHING IN BRAZIL HEADING \\ TO? TAKING A LOOK AT ITS ELEMENTS AND STATUS IN THE FIELD
}

\author{
¿PARA DÓNDE ESTÁN LLENDO LAS INVESTIGACIONES \\ SOBRE LA ENSEÑANZA DE GEOGRAFÍA EN BRASIL? UNA \\ MIRADA SOBRE LOS ELEMENTOS DE LA INVESTIGACIÓN \\ Y DEL LUGAR QUE ELLA OCUPA EN ESE CAMPO \\ Lana de Souza Cavalcanti - Universidade Federal de Goiás - Goiânia - Goiás - Brasil \\ Is.cavalcanti@uol.com.br
}

\begin{abstract}
Resumo
0 texto apresenta reflexões com base, sobretudo, em resultados de um estudo exploratório sobre o estado da arte da pesquisa sobre ensino no Brasil. Tal estudo teve como fonte principal de dados um levantamento de Teses e Dissertações nos Programas de Pós-Graduação em Geografia no Brasil. Para tanto, considerou-se o período de 2000 a 2015 . Os resultados do estudo confirmam indicações de que essa área tem tido nas duas últimas décadas avanços significativos e consolidação como campo investigativo.

Palavras-chave: Ensino de Geografia, pesquisa, pós-graduação em Geografia.
\end{abstract}

\section{Abstract}

This paper presents a discussion grounded mainly on results from an exploratory study on the state of the art of research on Geography teaching in Brazil. The study's main source of data was a survey on theses and dissertations submitted to Brazilian postgraduate Geography programs from 2000 to 2015. Results confirm that the field of Geography teaching has advanced significantly in the last two decades and has consolidated itself in research.

Keywords: Geography teaching, research, postgraduate Geography programs.

\section{Resumen}

El texto presenta reflexiones basadas, principalmente, en los resultados de un estudio exploratorio a respecto del estado actual de la investigación sobre la enseñanza en Brasil. Ese estudio tuvo como principal fuente de datos un análisis de las Tesis y disertaciones de los programas de Posgrado en Geografía en Brasil. Para eso, se consideró el período de 2000 a 2015. Los resultados del estudio confirman indicaciones de que el área ha tenido, en las dos últimas décadas, avances significativos y consolidación como campo investigativo.

Palabras-clave: Enseñanza de Geografía, investigación, Posgrado en Geografía.

\section{Introdução}

Em eventos da Geografia, especificamente aqueles da área do ensino de Geografia, como o Enpeg e o Fórum Nepeg de formação de professores ${ }^{1}$, 
tem sido apontado de modo recorrente que a pesquisa nesse campo tem avançado e ganhado legitimidade no contexto da Academia. A esse respeito, cabem alguns questionamentos: esse campo investigativo tem, de fato, avançado quantitativa e qualitativamente? Como tem sido esse avanço? Como se caracterizam as investigações realizadas nessa linha? É possível fazer um balanço da produção acadêmica nessa linha? Já existe uma compreensão clara sobre essa produção que resulta de investigações anteriores? E mais, que contribuições podem trazer/tem trazido um balanço como esse para o encaminhamento de novos estudos e para a prática docente com essa disciplina?

Com o propósito de trazer e desenvolver algumas respostas às perguntas anteriormente feitas, o texto faz uma contextualização do campo do ensino de Geografia no Brasil nos últimos 30 anos, ou seja, a partir da década de 1980. Mais especificamente, são apresentadas, na parte seguinte do texto, as linhas dos estudos que estão sendo realizados nos últimos 15 anos, fundamentando-se em levantamento dos títulos, resumos e palavras-chave de dissertações e teses nos programas de pós-graduação no País, com o objetivo de mapear as principais produções quanto aos temas tratados, às categorias de análise e às metodologias de pesquisa predominantes. Além dessa fonte de dados mais objetivamente produzidos e sistematizados, as considerações e as reflexões do texto também levam em conta minha experiência e produção nesse campo, além de análises correlatas feitas por outros colegas nessa área.

\section{A pertinência e a relevância de estudos na perspectiva de estado da arte}

Consciente das limitações dos estudos que pretendem fornecer um "estado da arte" de um campo do conhecimento com base em produções acadêmicas oficiais e divulgadas, não abarcando, portanto, os diferentes contextos, as relações institucionais, os debates em salas de aula e em eventos de diversas naturezas, entendo que, ainda assim, é relevante o esforço para elaborar reflexões/ análises com esse foco que, de todo modo, fornece diagnósticos indicativos de trajetórias de linhas de pesquisa, necessários tanto para avaliar o passado dessa produção quanto para apontar caminhos em direção ao seu avanço. Esses diagnósticos são importantes para o conjunto de pesquisadores dessa linha específica, pois permite perceber e divulgar o que já está encaminhado e o que 
está ainda por fazer, e também ele é útil para cada pesquisador individualmente, pois indica demandas para o avanço da reflexão, podendo auxiliá-lo na identificação da relevância de sua própria investigação para a área e para a sociedade.

As possibilidades de estudos dessa natureza giram em torno da elaboração de inventários dessa produção, identificando tendências, ênfases, escolhas metodológicas e teóricas. No entanto, no levantamento que fundamenta as reflexões deste texto ${ }^{2}$, limito-me à análise dos títulos, resumos e palavras-chave de teses e dissertações, produzidas em um período delimitado, buscando apreender aí temas, opções teóricas explícitas, objetivos e procedimentos metodológicos anunciados. A análise dos discursos dessa produção é feita com base em Bakhtin (1992), sendo, portanto, uma leitura crítica que envolve tanto o que está escrito, como a capacidade de apreensão do contexto em que tal escrita se deu. Destarte, trata-se de uma interpretação da escrita e do que não está escrito, feita por parte de quem faz a leitura. Da análise do material disponível nesse tipo de estudo exploratório, busco expor uma compreensão particular do conhecimento acumulado nesse campo, suas perspectivas teórico-metodológicas e seus limites.

Não pode ser negligenciado o propósito, em trabalhos de sistematização como esse, de consolidar um campo, pois ele permite a explicitação de suas principais preocupações, de suas bases de sustentação, tendências e temáticas investigadas, bem como apresenta indicadores de sua evolução histórica na produção acadêmica, as instituições que tem se destacado nessa produção, a distribuição geográfica dessa produção, os níveis de ensino e etapas escolares privilegiadas no conjunto dos estudos realizados. Enfim, estudos como esse frequentemente buscam explicitar uma compreensão do conhecimento acumulado em determinado campo, delimitando-se tempo e espaço. Como entendem Romanowski e Ens (2006, p. 38-39),

O interesse por pesquisas que abordam "estado da arte" deriva da abrangência desses estudos para apontar caminhos que vêm sendo tomados e aspectos que são abordados em detrimento de outros. A realização destes balanços possibilita contribuir com a organização e análise na definição de um campo, uma área, além de indicar possíveis contribuições da pesquisa para com as rupturas sociais. A análise do campo investigativo é fundamental neste tempo de intensas mudanças associadas aos avanços crescentes da ciência e da tecnologia. 
Para atingir tais propósitos, neste texto que trata especificamente da pesquisa sobre ensino de Geografia, é necessário ir além da simples identificação da produção; por isso, busca-se analisá-la, considerando o limite do material coletado (basicamente resumos de dissertações e teses e palavras-chave indicadas), categorizando-a, revelando seus enfoques e perspectivas e sintetizando a relevância social e acadêmica das pesquisas nesse campo. Entende-se que esse propósito está de acordo com os movimentos dos investigadores da área em diferentes escalas, fundamentando-se em manifestações de grupos de pesquisadores na área da didática da Geografia em diferentes lugares do Brasil; dos pesquisadores de países da América Latina, como pode ser verificado em Colóquios da REDLADGEO; investigadores da Espanha e Portugal, com as preocupações divulgadas e debatidas, por exemplo, no último encontro Geocrítica ${ }^{4}$; e a Comissão de Educação Geográfica da União de Geógrafos Internacionais - UGI ${ }^{5}$, que destaca o papel do ensino de Geografia para compreender o mundo atual e sua complexidade, e as demandas de investigação a respeito.

Essa reflexão não poderia ser feita sem levar em conta o contexto social e histórico em que ela se insere, e destacando-se nesse contexto os programas e as políticas públicas voltadas para a educação, que resultam de movimentos nesse contexto. Com efeito, os desdobramentos de estudos no campo do ensino de Geografia estão estreitamente relacionados com as demandas sociais que são colocadas em diferentes tempos e contextos, e muitas vezes essas demandas têm rebatimentos em implantação de tais programas e políticas. É o caso, por exemplo, dos Parâmetros Curriculares Nacionais, que fazem parte da política educacional da década de 1990, que objetivou disponibilizar orientações curriculares nacionais para todos os níveis do ensino e todas as matérias, e das Diretrizes para a formação de Professores, da década de 2000, que prescreveram orientações e estabeleceram formas de estruturar cursos para a formação de professores. Políticas como essas, e seguramente outras que foram e estão sendo elaboradas e implementadas mais recentemente, afetam direta ou indiretamente as práticas do ensino de Geografia, e isso, por sua vez, impõe uma agenda de debate e de estudos que interfere nas linhas de investigação nesse campo. Por esse caminho, é pertinente alertar que a compreensão mais ampla das temáticas estudadas e mesmo da metodologia das pesquisas requer a análise desse quadro social e histórico, ainda que essa análise não seja contemplada explicitamente nos limites desse texto. 
0 ensino de Geografia: a reflexão sobre esse objeto no contexto do movimento de renovação da década de 1980 e seus desdobramentos

Em minha própria produção intelectual, tenho procurado discutir e apresentar meu entendimento da distinção e relação entre as "geografias" que são praticadas na sociedade. Poder-se-ia dizer que há, nesse sentido: 1- a geografia cotidiana, aquele conhecimento espacial que é produzido e utilizado por todas as pessoas em sua constante lida com as coisas do mundo ao seu redor, que contém elementos do senso comum, ele próprio composto também por conhecimentos científicos; 2- a Geografia acadêmica, o conhecimento produzido por pesquisas no âmbito da ciência geográfica e sistematizado para ser veiculado na comunidade de geógrafos (incluindo os que estão em processo de formação inicial) e 3 - a Geografia escolar, a produzida, organizada e praticada nas escolas. São estruturações específicas, distintas, mas que tem como referência principal a ciência geográfica. A pesquisa no ensino de Geografia está nas fronteiras, nas interfaces dessas geografias praticadas, pois justamente leva em conta o que se tem produzido na ciência de referência, na prática da formação, na prática de ensino básico com essa disciplina e na prática cotidiana. Em relação às "geografias brasileiras", acadêmica e escolar, é relevante também considerar que elas têm histórias paralelas, sobretudo quando se considera sua institucionalização no início do século XX. Desde então, elas se "encontram", se influenciam mutuamente, guardando, mesmo assim, suas identidades, suas especificidades ${ }^{6}$. Nessa trajetória, costuma-se destacar a década de 1980, considerada referência do período em que ocorreu no Brasil o chamado "movimento de renovação da Geografia” (acadêmica e escolar), inicialmente marcado pela disputa de hegemonia de dois núcleos principais, um aglutinando a Geografia dita "tradicional”, que se mantinha tal como havia se estruturado nas primeiras décadas do século XX; e outro que representava uma Geografia nova, que buscava suplantar a tradicional, que se proclamava "crítica", com predomínio de uma orientação marxista7.

No contexto desse movimento, surgiram análises e propostas que tinham o propósito de denunciar o caráter oficial, utilitário e ideológico dessa ciência, alertando para sua falsa neutralidade e "inocência”, características que, segundo atestavam, estavam presentes fortemente na Geografia da sala de aula. Com isso, buscando impingir outras formas de trabalhar nessa área, investiu-se no avanço da compreensão do espaço, de sua historicidade e da sua relação dialética com a sociedade. 
Esse "movimento de renovação" da década de 1980, portanto, também focava o ensino de Geografia, atribuindo-lhe maior significado social. Com esse intuito, questionava-se sua estrutura convencional, que era dicotômica, fragmentada (composta por "partes estanques"), abordando de um lado os fenômenos naturais, e de outro, os humanos; ou como alertava Moreira (1987), havia uma estrutura padrão do discurso geográfico tradicional, a qual requeria superar; que era por ele simbolizada na forma de N-H-E, ou seja, os temas (os conteúdos geográficos escolares) eram tratados de modo fragmentado, agrupados sob a linha mestra da Natureza, do Homem e da Economia. A proposta era, então, elaborar uma nova estrutura, cujo eixo central era o espaço e as contradições sociais nele expressas, orientando-se pela explicação das causas e decorrências das localizações de certas estruturas espaciais.

Nesse período, as discussões sobre o que era a Geografia na escola, sobre o que seria necessário e importante ensinar, ficaram predominantemente a cargo de geógrafos de destaque no movimento de renovação, que estavam voltados para a discussão de todo o discurso e a prática da Geografia e suas matrizes epistemológicas e políticas, mas que não se configuravam como propriamente um pesquisador do campo do ensino, como são os casos de Ruy Moreira, Carlos Valter Porto Gonçalves, Ariovaldo Umbelino de Oliveira, José Willian Vesentini.

Além disso, é preciso salientar que, desde as primeiras formulações desse movimento, havia diversidade de entendimentos do que seria Geografia crítica, ou mesmo geografias críticas, ainda que se perceba certa predominância do discurso marxista, como já foi dito. Porém, essa diversidade foi mais explicitada e consolidada nos anos de 1990, resultando em um reconhecimento de uma Geografia plural e diversificada em sua temática e em suas abordagens teórico-metodológicas.

Na década de 1990, a sociedade vivenciou uma importante crise de referenciais, com a queda dos chamados blocos político-econômicos dos primeiro e segundo mundos, provocando na sequência o desmoronamento paulatino das experiências socialistas em diversos países, cujo marco principal foi a queda do Muro de Berlim, em 1989. O contexto dessa crise significou para o campo científico e educacional a ampliação e consolidação de diferentes referenciais interpretativos da realidade, que se revelavam mais complexos que aqueles modelos macro de análise, fundados nas chamadas "metanarrativas". Abriram-se, assim, possibilidades para a inclusão no cenário acadêmico de reflexões e propostas de leitura 
da realidade pós-modernas e pós-estruturalistas. A legitimação de novos referenciais teórico-metodológicos na Geografia foi marcante nesse período, e novas orientações para o trabalho docente com a Geografia também foram se reconstruindo. Surgiram propostas alternativas, articuladas mais direta e explicitamente a orientações pedagógico-didáticas, definindo diferentes métodos para o ensino de Geografia. Com essas novas orientações, reafirmou-se o papel relevante da Geografia na formação das pessoas, mas reconhecendo que mudanças relacionadas ao cotidiano espacial de uma sociedade globalizada, urbana, informacional, tecnológica, requerem uma compreensão do espaço que inclua a subjetividade, o cotidiano, a multiescalaridade, a comunicação, as diferentes linguagens do mundo atual. Nesse período, em razão da abertura de espaços institucionais para a pesquisa no ensino (notadamente expressas em dissertações e teses em Programas de Pós-Graduação na área) foi possível levantar de modo mais sistemático as frágeis ressonâncias do Movimento de Renovação da Geografia (ou poderia ser chamado de Geografias Críticas) na prática de ensino. É o que atesta Zanatta (2010, p. 303):

Percebe-se, também, que a situação real do ensino de Geografia na década de 1990 mostra que as propostas feitas em torno do papel transformador da Geografia Crítica foram modestas e pouco expressivas. Em contraposição, verifica-se que, ao longo da década de 1990, aumentou consideravelmente a participação de geógrafos formadores de professores na pesquisa dirigida ao ensino de Geografia, com visível interesse em buscar, na Pedagogia e na Didática, aportes necessários à melhoria da formação do professor de Geografia.

Assim, nas décadas de 1990 e de 2000, consolidou-se a área de pesquisa no ensino, na graduação, na pós-graduação e em rede com professores da escola básica. Essa área ganhou espaço acadêmico, profundidade teórica, amplitude temática. A pesquisa passou a focar temas diversificados e a sugerir abordagens, como as que serão tratadas no próximo item do texto.

Recentes caminhos investigativos no ensino de Geografia: o que revelam estudos realizados no âmbito da pós-graduação no Brasil

Em estudo anterior (Cavalcanti, 2010a e 2010b), motivada pelo objetivo de identificar as linhas de propostas mais presentes na investigação na área do ensino de Geografia, que tiveram maior ressonância na prática 
docente, com base em trabalhos realizados e publicados, pude sistematizar algumas orientações metodológicas para o ensino dessa disciplina, entre as quais podem ser destacadas: 1- O lugar como referência no tratamento dos conteúdos geográficos; 2- Formação de conceitos geográficos instrumentalizadores do pensamento espacial; 3- Desenvolvimento da capacidade de leitura e mapeamento da realidade pela linguagem gráfica e cartográfica; 4- Desenvolvimento da habilidade de lidar com linguagens "alternativas" (música, poesia, cinema, literatura, jogos eletrônicos e outros produtos digitais) na análise geográfica; 5- Tratamento crítico das temáticas físico-naturais (incluindo temáticas ambientais).

É possível afirmar, com base nas propostas metodológicas identificadas e na experiência prática, que houve avanços no entendimento e nas práticas docentes com essa matéria. No entanto, estão presentes também, no cotidiano das escolas, práticas tradicionais, ainda distantes de propostas apontadas em estudos acadêmicos. De todo modo, tais propostas resultam de um investimento sistemático na investigação sobre o ensino de Geografia, que tem se tornado mais visível desde a década de 1990, e que se consolidou nesses primeiros anos do século XXI, como foi possível verificar em levantamento feito em Cavalcanti, Callai, Castellar (2012). Nesse levantamento, feito em dissertações e tese e também em periódicos identificados entre 2000 e 2009, confirmou-se a ampliação da investigação e publicação nesse campo.

Esse investimento na pesquisa sobre ensino de Geografia tem sido realizado de modo significativo em Programas de Pós-Graduação (em Geografia e em Educação). Na verdade, é preciso dizer que a investigação geográfica, de um modo geral, tem sido feita em boa parte em articulação aos Programas de Pós-Graduação da área. A configuração, a distribuição e as linhas temáticas desses Programas tem sido preocupação de vários estudiosos ${ }^{8}$, que buscam compreender a trajetória da pesquisa em Geografia. Em comum, apontam para sua expressiva concentração no sudeste e sul do País (que tem relação com a concentração econômica e produtiva nessas regiões), pelo menos até os anos de 1990, sua gradativa expansão nas duas últimas décadas, acompanhada de uma tendência à interiorização e distribuição mais equitativa dos mesmos pelo território nacional. Portanto, embora se tenha a consciência de que a pesquisa no ensino de Geografia não é feita somente nesse âmbito, é possível concluir que um estudo de linhas de pesquisa no ensino de Geografia e de teses e 
dissertações nessa área revelam importantes caminhos que estão sendo trilhados no sentido da reflexão teórica e das proposições para o ensino de Geografia no Brasil.

Como analisa, por exemplo, Lencioni (2013), mudanças nos termos das linhas de pesquisa nos Programas de Pós- Graduação em Geografia, de palavras como natureza para ambiente; cartografia para geoprocessamento; planejamento para gestão e ordenamento, mais que adesão a "modismos", indicam o contexto da pesquisa e as opções teórico-metodológicas adotadas.

Com relação especificamente ao contexto da pesquisa sobre ensino realizada em Programas de Pós-Graduação em Geografia no Brasil, observa-se que ela acompanha o movimento geral da área, de pouca demonstração quantitativa nos anos de 1970 e de 1980 e uma expressiva expansão na década de 1990 e de 2000, concentrada visivelmente no sudeste, ainda que se constate uma tendência à distribuição mais equitativa da produção. Como atesta Pinheiro (2005, p. 53), os dados de sua pesquisa comprovam "a existência de uma concentração das pesquisas sobre o ensino de Geografia na Região Sudeste, com aproximadamente 68\% do total, sendo metade desse percentual realizada nas universidades do estado de São Paulo"9. Nessa pesquisa, o autor chama a atenção para a diversidade dos focos temáticos das pesquisas acadêmicas sobre o ensino de Geografia feitas nos programas de pós-graduação de todo o país. Sobre essa diversidade, ele identificou 10 focos temáticos, por ordem de importância quantitativa: 1- prática docente e educativa; 2- representações espaciais; 3- educação ambiental; 4 - Formação de professores; 5- características dos alunos; 6- livro didático; 7- currículos e programas; 8- formação de conceitos; 9- conteúdo-método; 10- história da geografia.

A diversidade temática, no âmbito das investigações sobre ensino de Geografia, foi também categorizada no levantamento realizado por Callai, Castellar e Cavalcanti (2012). As categorias identificadas como representativas dos temas dos estudos encontrados foram: 1- Formação de conceitos; 2- Ensino em contextos diferenciados; 3- História da Geografia Escolar; 4- Metodologias; 5- Diferentes linguagens; 6 - Formação, saberes e práticas docentes; 7- Currículos e políticas públicas; 8 - Livros didáticos.

A ampliação de Programas de Pós-Graduação em Geografia e da institucionalização de linhas de pesquisa em ensino de Geografia ${ }^{10}$ é uma tendência visível, embora ainda seja aparentemente uma área pouco explorada. É o que observa Lencioni (2013, p. 17), a esse respeito: “Quanto 
ao ensino da geografia, embora esse tema figure nas linhas de pesquisa dos programas, ainda aparece de forma tímida [...]".

Buscando ampliar essa visão panorâmica da investigação na área, e considerando-se exclusivamente o âmbito dos programas de pós-graduação em Geografia, com os dados levantados pelo Grupo NUCEF, anteriormente referido, foi possível identificar que, dos 62 Programas identificados em 2015, 17 tem linhas específicas de Ensino de Geografia, conforme tabela a seguir:

Tabela 1 - Linhas de Pesquisa sobre Ensino de Geografia em Programas de Pós-Graduação em Geografia - Brasil, 2010-2015

\begin{tabular}{|c|c|c|c|c|c|}
\hline Programas & $\begin{array}{l}\text { Ano de } \\
\text { Criação }\end{array}$ & $\begin{array}{l}\text { Mestrado/ } \\
\text { Doutorado }\end{array}$ & $\begin{array}{l}\text { No. de } \\
\text { Linhas de } \\
\text { pesquisa }\end{array}$ & $\begin{array}{c}\text { Linhas de Pesquisa no } \\
\text { Ensino }\end{array}$ & $\begin{array}{c}\text { Número de trabalhos } \\
\text { sobre ensino } \\
\text { M D T }\end{array}$ \\
\hline 11 & $1995 / 2006$ & Mest./Dout. & 3 & $\begin{array}{l}\text { Ensino-aprendizagem em } \\
\text { Geografia }\end{array}$ & $32-840$ \\
\hline 14 & $1998 / 2003$ & Mest./Dout. & 3 & $\begin{array}{c}\text { Ensino, Métodos e Técnicas } \\
\text { em Geografia }\end{array}$ & $10-010$ \\
\hline 16 & 2013 & Mest. & 2 & $\begin{array}{l}\text { Espaço, Ensino e } \\
\text { Representação }\end{array}$ & $0-000$ \\
\hline 22 & 2004 & Mest./Dout. & 3 & Educação Geográfica & $23-023$ \\
\hline 23 & $1976 / 2004$ & Mest./Dout. & 4 & $\begin{array}{l}\text { Educação, cultura, política } \\
\text { e inovação na produção } \\
\text { contemporânea do espaço }\end{array}$ & $02-002$ \\
\hline 24 & 2011 & Mest. & 2 & Ensino de Geografia & $12-012$ \\
\hline 30 & 2006 & Mest. & 3 & $\begin{array}{l}\text { Educação e Ensino de } \\
\text { Geografia }\end{array}$ & $06-006$ \\
\hline 36 & 2013 & Mest. & 3 & Ensino de Geografia & $03-003$ \\
\hline 41 & $1999 / 2004$ & Mest./Dout. & 3 & Ensino de Geografia & $53-1164$ \\
\hline 43 & 2012 & Mest. & 2 & Ensino de Geografia & $04-004$ \\
\hline 45 & $1990 / 2001$ & Mest./Dout. & 5 & $\begin{array}{l}\text { Eixo comum: Geografia em } \\
\text { Processos educativos }\end{array}$ & $00-000$ \\
\hline 47 & 2013 & Mest. & 3 & Educação, saúde e cultura & $00-000$ \\
\hline 51 & $1976 / 1983$ & Mest./Dout. & 5 & $\begin{array}{l}\text { Geografia, ensino e } \\
\text { Cartografia escolar }\end{array}$ & $18-1735$ \\
\hline 53 & $1970 / 1946$ & Mest./Dout. & 7 & Geografia, educação e ensino & 30- 2050 \\
\hline 57 & 2015 & Mest. & 3 & $\begin{array}{l}\text { Processos Formativos, } \\
\text { práticas e ensino de Geografia }\end{array}$ & $00-000$ \\
\hline 58 & 2015 & Mest. & 3 & $\begin{array}{c}\text { Geografia escolar: formação } \\
\text { de professor e educação } \\
\text { geográfica }\end{array}$ & $00-000$ \\
\hline
\end{tabular}




\begin{tabular}{|c|c|c|c|c|c|}
\hline 62 & 2014 & Mest. Prof. & 2 & $\begin{array}{c}\text { Metodologia do ensino de } \\
\text { Geografia } \\
\text { Saberes geográficos no } \\
\text { espaço escolar }\end{array}$ & $00-000$ \\
\hline $\begin{array}{c}\text { Total na área } \\
\text { de ensino }\end{array}$ & - & - & - & 17 & 245 \\
\hline
\end{tabular}

M-Mest.: mestrado; Mest. Prof.: mestrado profissional; T- total.

Fonte: Elaborado pela autora.

A espacialização desses programas pode ser visualizada no mapa a seguir:

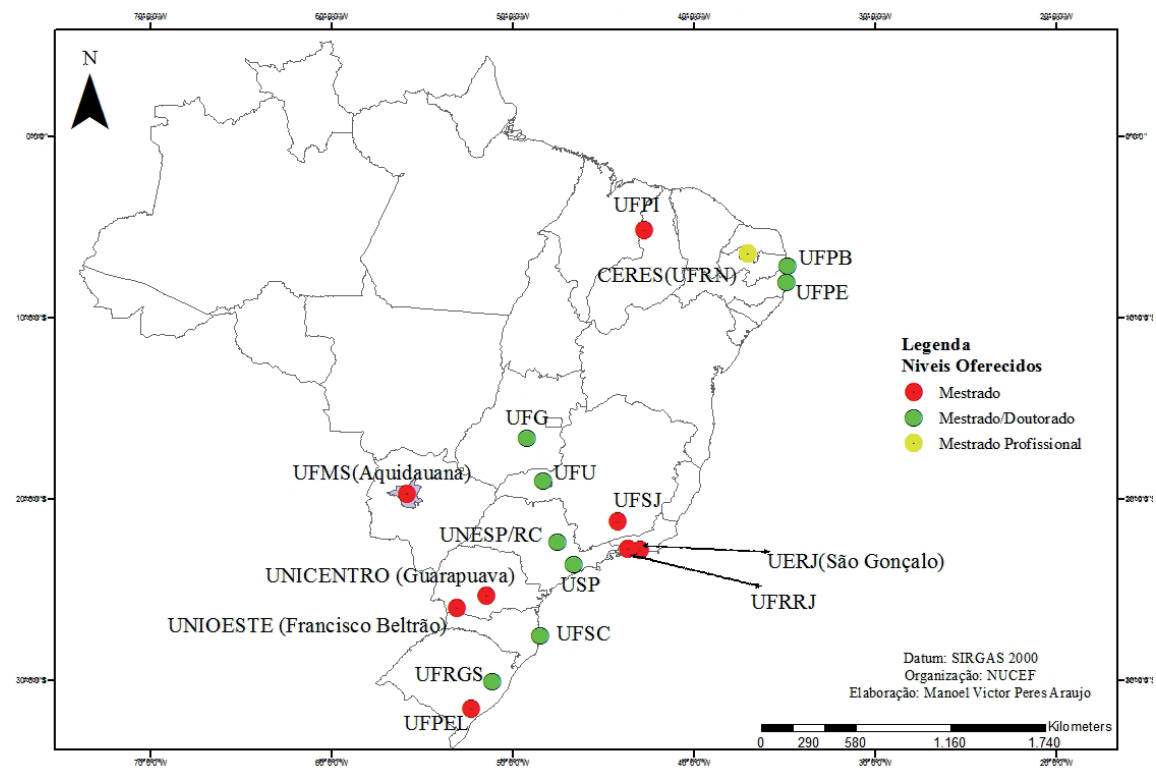

Figura 1 - Espacialização das linhas de Pesquisa de ensino de

Geografia em programas de Pós-Graduação - 2015

Fonte: Elaborado por Manoel Victor Araújo.

Desses 17 programas, com linhas específicas para a pesquisa no ensino de Geografia, vale destacar que se trata de um quadro diversificado, sendo que nove têm cursos de mestrado e doutorado (e o restante com 
apenas mestrado) e oito são cursos mais antigos e consolidados, com criação anterior a 2010. Nesse conjunto, há um Programa que é de Mestrado Profissional, com área de concentração no Ensino de Geografia, e duas linhas de pesquisa, ambas ligadas diretamente ao ensino. A respeito da denominação da linha de pesquisa nesses Programas, há uma predominância dos termos "Ensino de Geografia”, e também a presença do termo mais abrangente "Educação Geográfica”, além da articulação com outros termos, como saúde, o que revela uma intenção de articular tendências diferentes da pesquisa e suas interfaces.

Para traçar um perfil mais atualizado das pesquisas nesse campo, contribuindo assim para referendar os outros estudos já realizados, realizou-se um estudo dos resumos e palavras-chave ${ }^{11}$ de 430 trabalhos, sendo 338 dissertações e 92 teses, do total de 62 Programas da Geografia, estudo delimitado ao período de 2000/2015. Neste perfil, utilizou-se a mesma categorização de pesquisa anterior (Callai, Castelar; Cavalcanti, 2012), com pequenos ajustes para abrigar a temática abordada nesses trabalhos. Esse conjunto de trabalhos categorizados por eixos temáticos está representado na tabela a seguir:

Tabela 2 - Eixos temáticos em Teses e Dissertações sobre

Ensino de Geografia (Brasil, 2010-2015)

\begin{tabular}{|c|c|c|c|c|c|c|c|c|c|c|c|c|c|c|c|c|c|}
\hline Eixo & \multicolumn{2}{|c|}{$\mathbf{1}$} & \multicolumn{2}{|c|}{ 2 } & \multicolumn{2}{|c|}{$\mathbf{3}$} & \multicolumn{2}{|c|}{$\mathbf{4}$} & \multicolumn{2}{|c|}{$\mathbf{5}$} & \multicolumn{2}{|c|}{$\mathbf{6}$} & \multicolumn{2}{|c|}{$\mathbf{7}$} & \multicolumn{2}{|c|}{$\mathbf{8}$} & \\
\cline { 1 - 3 } Nível & $\mathbf{M}$ & $\mathbf{D}$ & $\mathbf{M}$ & $\mathbf{D}$ & $\mathbf{M}$ & $\mathbf{D}$ & $\mathbf{M}$ & $\mathbf{D}$ & $\mathbf{M}$ & $\mathbf{D}$ & $\mathbf{M}$ & $\mathbf{D}$ & $\mathbf{M}$ & $\mathbf{D}$ & $\mathbf{M}$ & $\mathbf{D}$ & N/I \\
\hline Otdd & 69 & 07 & 31 & 02 & 12 & 04 & 67 & 19 & 24 & 04 & 77 & 37 & 28 & 10 & 22 & 04 & 13 \\
\hline$\%$ & 6,04 & 1,62 & 7,20 & 0,46 & 2,79 & 0,93 & 15,48 & 4,41 & 5,58 & 0,93 & 17,90 & 8,60 & 6,27 & 2,32 & 5,11 & 0,93 & 3,02 \\
\hline Total & \multicolumn{2}{|c|}{17,66} & \multicolumn{2}{|c|}{7,66} & \multicolumn{2}{|c|}{3,72} & \multicolumn{2}{|c|}{19,89} & \multicolumn{2}{|c|}{6,41} & \multicolumn{2}{|c|}{26,50} & \multicolumn{2}{|c|}{8,59} & 5,04 & 3,02 \\
\hline
\end{tabular}

M: mestrado; N/l: não identificado.

Fonte: Elaborado pela autora.

A categorização dos trabalhos nesses Eixos temáticos, já foi dito, foi feita com base na leitura dos títulos, resumos e palavras-chave, e resulta ao final em escolhas do pesquisador quanto ao eixo marcante, admitindo-se a possibilidade de outras escolhas, pois em muitos casos é possível associar um trabalho a mais de um eixo, ou mesmo a um ou outro.

Dos oito eixos definidos, três deles tiveram maior incidência de trabalhos: o eixo 1 - Formação de Conceitos, com 76 pesquisas de mestrado e doutorado (17,66 do total); 4 - Metodologias, com 86 dos trabalhos 
(19,89\% do total) e 6 - Formação, saberes e práticas docentes, com 114 dos trabalhos $(26,50 \%)$.

A Formação de Conceitos, Eixo Temático 1 (e neste eixo foram incluídos estudos sobre aprendizagem dos alunos em geral), identificado em $17,66 \%$ dos trabalhos, versam sobre os conceitos em geral, ou sobre um dos conceitos mais gerais, como lugar, território, paisagem, ambiente, ou ainda sobre conceitos mais específicos da análise geográfica, como cultura, cerrado, campo, cidade, geopolítica, relevo, migração.

Em relação aos temas contemplados nos estudos pertencentes ao eixo temático Metodologias (Eixo 4), os destaques são de estudos voltados para o uso de tecnologias da informação e comunicação, em especial as geotecnologias; para o uso de linguagens diferenciadas, por exemplo música e história em quadrinhos; sobre alfabetização cartográfica (digital e tátil), destacando-se os mapas mentais, e também trabalhos que exploram a potencialidade de trabalhos de campo/ estudo do meio para a aprendizagem geográfica.

Nos estudos realizados com a temática focada no professor (Eixo 6), sua formação, sua prática e seus saberes, destacam-se predominantemente os que se dedicam a analisar a formação inicial e os estágios nessa formação, embora haja também estudos sobre a formação continuada; também estão presentes em boa quantidade estudos referentes às práticas docentes com determinados conteúdos.

Em relação aos estudos que abordam o ensino de Geografia em contextos diferenciados (eixo 3), destacam-se os que se voltam para a análise da educação do campo, a educação em comunidades específicas (indígenas, quilombolas), em escolas que atendem alunos com deficiências visuais ou auditivas. O desafio desses estudos é o de compreender e/ou propor práticas docentes que respeitem as especificidades dos sujeitos ali envolvidos e proporcionem condições para que essas especificidades sejam respeitadas e sejam utilizadas a favor de sua aprendizagem geográfica.

Os estudos sobre o Livro Didático (Eixo 8) focalizam em sua trajetória histórica, ou nos modos como ele é utilizado no cotidiano das aulas, ou ainda como ele aborda conteúdos específicos, como natureza, lugar, processo migratório. Em todos eles, e ainda em outros estudos que o tomam como objeto subsidiário de análise, há uma compreensão de que o Livro Didático é um recurso muito importante para o ensino de Geografia, muito utilizado nas atividades escolares e que por isso mesmo deve ser objeto constante de análise, do professor e dos especialistas. 
Entre os eixos menos contemplados destacam-se o 3- Historia da Geografia Escolar e o 7- Currículos e Políticas Públicas. Esse dado traz uma preocupação: por que são realizados poucos estudos sobre essas temáticas? Elas não são relevantes? Elas são consideradas objetos mais específicos de outras áreas (História do Pensamento Geográfico e Políticas Educacionais e Currículo Escolar, respectivamente)? Haveria alguma relação entre essa constatação e fragilidades teóricas da área? Independentemente das respostas a essas questões, creio que para o âmbito desse artigo é pertinente apontar para essas possíveis lacunas da linha de pesquisa aqui analisada, e destacá-las com o propósito de indicação de demandas para investigações futuras.

Em relação às palavras-chave arroladas junto aos resumos dos 430 trabalhos, objetos dessa análise, foram excluídas do rol a serem estudadas aquelas que foram consideradas muito genéricas e de pouco valia para identificar alguma tendência dos estudos, como "ensino", "ensino de Geografia”, “Geografia escolar”, “educação”, “educação geográfica”, e aquelas, pelo contrário, muito específicas, que se referiam ao local onde o estudo foi realizado, à escola específica, ao tema específico, ou à metodologia de pesquisa. O objetivo dessa análise foi o de ampliar a compreensão das principais preocupações que têm norteado os estudos nessa área, por isso buscou-se identificar palavras que pudessem articular-se aos eixos temáticos. O resultado foi o trabalho com um conjunto de 858 palavras. As palavras foram agrupadas por sua recorrência, em primeiro lugar levando-se em consideração sua repetição literal, e em segundo lugar buscando-se aproximações de significados correlatos. A partir dessas orientações, os agrupamentos realizados geraram a seguinte tabela:

Tabela 3 - Palavras-chave de Teses e Dissertações sobre ensino de Geografia. Brasil, 2000/2015

\begin{tabular}{|c|c|c|c|}
\hline Agrupamentos & Palavras recorrentes & Quantidade de palavras & Total \\
\hline \multirow{3}{*}{$\begin{array}{c}\text { 1-Palavras referentes ao } \\
\text { professor, sua formação e seus } \\
\text { saberes }\end{array}$} & Formação de professores & 50 & \multirow{3}{*}{130} \\
\hline & $\begin{array}{l}\text { Conhecimento e prática } \\
\text { docente }\end{array}$ & 68 & \\
\hline & Processo de formação inicial & 12 & \\
\hline \multirow{2}{*}{$\begin{array}{c}\text { 2- Palavras referentes ao } \\
\text { aluno e metodologias de } \\
\text { aprendizagem }\end{array}$} & Aprendizagem e aluno & 35 & \multirow{2}{*}{104} \\
\hline & Metodologia & 69 & \\
\hline
\end{tabular}




\begin{tabular}{|c|c|c|c|}
\hline \multirow{4}{*}{$\begin{array}{l}\text { 3-Palavras referentes à escola } \\
\text { e ao currículo }\end{array}$} & Escola e sua estrutura & 34 & \multirow{4}{*}{189} \\
\hline & Currículo e Livro didático & 91 & \\
\hline & Propostas pedagógicas & 11 & \\
\hline & Nível de ensino & 53 & \\
\hline \multicolumn{3}{|c|}{ 4-Palavras referente a temas sociais } & 14 \\
\hline $\begin{array}{l}\text { 5-Palavras referentes a um } \\
\text { conteúdo geográfico }\end{array}$ & Espaço e suas adjetivações & 32 & \multirow{4}{*}{322} \\
\hline & Cartografia & 90 & \\
\hline & $\begin{array}{l}\text { Cartografia, linguagem e } \\
\text { inclusão }\end{array}$ & 12 & \\
\hline & $\begin{array}{l}\text { Conceitos e conteúdos } \\
\text { geográficos diversos }\end{array}$ & 188 & \\
\hline \multicolumn{3}{|c|}{ Outras palavras } & 99 \\
\hline \multicolumn{3}{|c|}{ Total } & 858 \\
\hline
\end{tabular}

Fonte: Elaborado pela autora.

Em relação ao primeiro agrupamento, percebe-se um grande destaque de palavras que tem referência clara ao professor. São palavras que se somam aos resumos e títulos dos trabalhos, que revelou ser um eixo temático de destaque, o que reforça a percepção de que há efetiva preocupação dos estudos com esse foco.

Em relação ao outro agrupamento, que tem foco no aluno e em suas aprendizagens, foram agrupadas palavras mais diretamente referentes aos alunos, como: aluno, jovem, juventude, autoria dos alunos, processo de aprendizagem, construção de conhecimento, entre outros; e palavras que revelam preocupação direta com possibilidades metodológicas para a aprendizagem dos alunos (o que também está reforçando o destaque ao eixo temático 4, conforme abordado anteriormente). As palavras de destaque sobre metodologia são: trabalho de campo, metodologia de ensino, e as Tecnologias da Informação e Comunicação - TICs (associadas às palavras do tipo educação online, ambientes virtuais de aprendizagem, objetos de aprendizagem, internet, softwares educacionais, jogos eletrônicos, entre outros).

Em relação ao $3^{\circ}$ agrupamento, merece destaque o item sobre referências curriculares, e nesse grupo o Livro Didático, que sozinho é citado 26 vezes como palavra-chave, reforçando também seu destaque anterior, representado no Eixo Temático 8.

O $5^{\circ}$ agrupamento também merece destaque, pelo grande número de palavras identificadas, reforçando a preocupação com os conteúdos 
geográficos e o desafio da formação de conceitos e habilidades dos alunos. Nesse grupo, destaco as referências à Cartografia, com palavras recorrentes como mapas mentais, cartografia escolar, alfabetização cartográfica, linguagem cartográfica, além de palavras que estão associadas ao sistema de informação geográfica (SIG), sensoriamento remoto, imagens de satélite. Outro destaque são os conceitos que mais aparecem no rol de palavras-chave, denotando os conteúdos geográficos mais trabalhados nesses estudos, entre eles podem ser destacados, pelo número de citações: vida cotidiana/cotidiano (dez vezes); educação ambiental e suas derivações, do tipo legislação ambiental, meio ambiente, degradação, sustentabilidade (46 vezes); lugar (26 vezes); cultura (seis vezes), cidade e derivações (nove vezes), educação do campo (seis vezes) e paisagem (seis vezes).

Em relação à metodologia dos estudos que foram analisados, tomando como base a indicação explícita nos resumos ou a inferência a partir da descrição dos passos e procedimentos metodológicos ${ }^{12}$, foi possível concluir que a grande maioria dos estudos configura-se como pesquisa qualitativa (nos resumos de 276 trabalhos, o que significa $64 \%$ do total, foi possível identificar uma opção explícita ou implícita pela abordagem qualitativa), em sua ampla acepção, variando entre os estudos etnográficos e os que se articulam com dados quantitativos tratados estatisticamente. Essa modalidade de pesquisa caracteriza-se nos trabalhos como estudos de práticas e realidades empíricas de situações escolares específicas, com objetivo de estudos exploratórios, descritivos, de casos, muitas vezes configurando-se como pesquisa participante ou mesmo pesquisa-ação. Os instrumentos de análise mais frequentemente utilizados são: observação de aulas, de cotidiano escolar; entrevistas e/ou questionários aos alunos e professores; grupos focais ou grupos de discussão; narrativas de história de vida de professores e/ou alunos; "aplicação" de propostas alternativas ao problema estudado.

Enfim, essa é uma leitura possível do conjunto de trabalhos identificados nos Programas, no período de 2000 a 2015. Outras leituras são possíveis e necessárias para compreender melhor esse conjunto, conforme já foi salientado. Para o momento, ele tem o papel de confirmar dados anteriores, apontando para a expansão dos estudos nessa área, para sua diversidade temática, para uma consolidação dos seus resultados no sentido de qualificar o pensamento e a prática de ensino de Geografia. 
Como fica o campo da pesquisa no ensino de Geografia? Ou considerações provisórias sobre o lugar da pesquisa sobre ensino de Geografia

Como pesquisadora nesse campo há mais de vinte anos e como professora e participante de vários eventos que focam a Geografia e o Ensino de Geografia, entendo que se pode afirmar que esse é um campo de estudos que tem tido sua relevância reconhecida na academia e na prática social - a prática de ensino, especificamente. Essa relevância está fundada na complexidade do seu objeto de análise - o ensino de Geografia em suas diferentes modalidades, níveis, e contextos - e de sua problemática. Por isso mesmo, sua expansão e sua consolidação no âmbito dos Programas de Pós-Graduação no País são tão importantes quanto necessárias para a continuidade dos estudos na área, para o aprofundamento de suas reflexões teóricas e para a eficácia de suas propostas de intervenção na realidade das práticas de ensino e aprendizagem em Geografia.

Sabe-se que as mudanças mais estruturais da educação e do ensino escolar extrapolam o escopo das pesquisas acadêmicas, pois estão mais dependentes das políticas públicas dirigidas à educação e às escolas como um todo. No entanto, pesquisas acadêmicas sobre o ensino de disciplinas específicas, como é o caso da Geografia, dão provisão teórica e empírica para os movimentos, institucionais ou não, que reivindicam tais mudanças.

Além disso, a consolidação desse campo de pesquisa contribui de forma bastante salutar para a área de Geografia como um todo, pois, sendo um campo que se dedica a uma importante prática dessa área, seu avanço como ciência e como reflexão da realidade depende desse campo específico. Dessa maneira, é relevante constatar que há atualmente 17 programas que têm uma linha específica dedicada a essa temática, e que, além disso, foi possível coletar dados de trabalhos (mestrado e doutorado) que tratam do tema e estão abrigados em linhas mais gerais que tangenciam o ensino, tornando possível, para esse texto, tomar como objeto de análise 430 trabalhos, 245 abrigados em linhas específicas do ensino e outros 185 em outras linhas ${ }^{13}$. Outro fator que merece destaque nessa análise é que dos 17 programas com linhas específicas no ensino, oito são de mestrados recém-criados, alguns ainda sem o tempo hábil para ter, até o ano de 2015 (limite do período analisado), dissertações concluídas, ainda que se suponha que várias delas estão em fase de desenvolvimento. 
Por conseguinte, os dados atestam a consolidação dessa linha de pesquisa, sua diversidade temática, sua institucionalização na pós-graduação, o que permite contestar a afirmação de que se trata de uma área "que aparece de forma tímida" nos programas, pelo contrário, os dados permitem afirmar que há, de fato, uma presença significativa dessa linha.

\section{Notas}

1 Enpeg é o Encontro Nacional de Prática de Ensino de Geografia, que acontece a cada dois anos em diferentes cidades do Brasil, com o objetivo de congregar pesquisadores da área, para a apresentação de suas pesquisas e para o debate de temas relevantes na época. Fórum Nepeg é um encontro de pesquisadores da Didática da Geografia, que envolve a formação de professores na área, e que acontece a cada dois anos, sob a coordenação do Núcleo de Estudos e Pesquisa em Educação Geográfica (NEPEG), sob a responsabilidade de professores da Universidade Federal de Goiás e da Universidade Estadual de Goiás.

2 O levantamento foi realizado pelo grupo de estudos NUCEF - Núcleo de Pesquisa sobre Currículo, Ensino e Formação de Professores, coordenado por Lucineide Mendes Pires e sediado no LEPEG - Laboratório de Pesquisa em Educação Geográfica do IESA/UFG. Esse levantamento tomou como base de consulta a relação de teses e/ou dissertações disponíveis nos sites dos Programas, nas bibliotecas digitais e/ ou na Plataforma Sucupira (Capes). A conclusão desse trabalho e da base de dados dele resultante tem tido algumas dificuldades, entre as quais merece destaque a dificuldade de acesso aos dados dos Programas, seja pela configuração dos sites, seja pela falta de informação disponível (dos títulos, dos resumos e/ou de palavraschaves) e/ou desatualização dos mesmos. Acredito que esse é uma demanda importante para os Programas e uma tarefa a ser realizada coletivamente.

3 REDLADGEO é uma rede de investigadores da América Latina que tem o propósito de congregar a discussão dessa temática do ensino de Geografia no âmbito da America latina.

4 Refiro-me ao XIII Colóquio Internacional de GEOCRÍTICA, realizado em Barcelona, no período de 5 a 12 de maio de 2014 .

5 Conferir em "The 2016 International Charter on Geography Education", Carta UGI - 2016 assinada por Vladimir Kolossov. 
6 Minha compreensão dessas duas estruturações da Geografia - a acadêmica e a escolar - está explicitada em Cavalcanti (2008).

7 É interessante, para aprofundar o entendimento das propostas de análise geográfica desse período (com desdobramento para as discussões no ensino), considerar as ponderações de Zanatta (2010), de Moraes (1989) e de Vesentini $(1992,1995)$ sobre as diferentes orientações tanto do que era chamado de Geografia Clássica (ou tradicional) quanto do que recebia o rótulo de Geografia Crítica (ou críticas, com inclinações mais para um marxismo humanista ou para um marxismo estruturalista).

8 Sobre esse tema conferir: Guidugli (1986), Carlos (2003), Suetergaray (2003), Pinheiro (2005), Silva (2011), Lencioni (2013), entre outros.

9 A pesquisa desse autor teve como suporte um estudo de 277 dissertações de mestrado e 40 teses de doutorado, defendidas em Programas de Geografia e de Educação, nas diferentes regiões do Brasil, até o ano de 2003.

10 Chama-se a atenção aqui para o fato de que as pesquisas nessa temática não estão circunscritas às linhas de pesquisa declaradamente voltada a ela; pois identificam-se muitas pesquisas sobre ensino de Geografia realizadas em diferentes linhas e por orientadores que não tem essa temática como centro de suas preocupações acadêmicas e investigativas, mas que reconhecem a relevância de estudos sobre ela. No entanto, a institucionalização de linhas especificamente voltadas para esse foco evidencia um reconhecimento e uma legitimidade que é importante evidenciar no exercício de compreender os caminhos da área.

11 Destaca-se que nem todos os trabalhos estavam com seus resumos disponíveis nos veículos considerados para a consulta, o que levou a que fossem incluídos no levantamento com a consideração apenas dos seus dados parciais.

12 A leitura desses resumos permite perceber sua relevância como referência para pesquisa bibliográfica de estudos posteriores, para revisão bibliográfica, mas também essa leitura permitiu identificar fragilidades na sua estruturação, em alguns casos com pouca informação, dificultando ter por meio dele uma ideia mais geral do tipo de trabalho realizado: a problemática, os objetivos, a metodologia, as fontes fundamentais e os resultados alcançados. 
13 Esses trabalhos foram os possíveis de identificar pelo levantamento realizado pelo NUCEF, como já foi destacado, e tomou-se como base o conjunto identificado para realizar a análise pretendida no texto por entender que ele já era suficiente, pois representava um número significativo da produção em todo o território nacional, em todos os programas. O levantamento foi realizado com rigor e seriedade pelo grupo de pesquisa, por meio de um trabalho exaustivo de busca, embora tenha-se consciência de sua incompletude, pois sabe-se que muitos trabalhos não foram coletados, por dificuldades no site do Programa ou na Plataforma Sucupira, por problemas com a própria metodologia de coleta, ou mesmo por dificuldades técnicas para o acesso e a disponibilização dos dados. O fato é que se sabe da existência de muitos outros trabalhos que focam essa temática tanto nos programas de Geografia como nos programas em Educação do País, mas que aqui não foi possível considerar.

\section{Referências}

BAKHTIN, M. Marxismo e filosofia da linguagem. São Paulo: Hucitec, 1992.

CALLAI, H. C.; CASTELLAR, S. V.; CAVALCANTI, L S. Tendências da pesquisa sobre o ensino de cidade na Geografia e suas contribuições para a prática docente. In: ALMEIDA, M. G.; OLIVEIRA, K. A. T. de; ARRAIS, T. A. Metrópoles: teoria e pesquisa sobre a dinâmica metropolitana. Goiânia: Cânone Editorial, 2012.

CARLOS, A. F. A. Questões para a construção de uma política de pós-graduação em Geografia. Revista da Anpege (Associação Nacional de Pós-Graduação em Geografia). São Paulo, n. 1, p. 71-83, 2003.

CAVALCANTI, L. S. Concepções Teórico-metodológicas da Geografia escolar no mundo contemporâneo e abordagens no ensino. In: DALBEN, A.; DINIZ J.; LEAL, L. SANTOS, L. (Org.). Convergências e Tensões no campo da formação e do trabalho docente. 1. ed. Belo Horizonte: Autêntica, 2010a.

. A Geografia e a realidade escolar contemporânea: avanços, caminhos e alternativas. In: I SEMINÁRIO NACIONAL: CURRÍCULO EM MOVIMENTO: Perspectivas Atuais, 2010, Belo Horizonte. Anais do I Seminário nacional: Currículo em Movimento: perspectivas atuais, 2010b.

KOLOSSOV, V. The 2016 International Charter on Geography Education - Carta da UGI, 2006. Disponível em: <http://www.igu-cge.org/Charters-pdf/Draft\%20 Charter\%20IGU-CGE\%20June\%2011th\%202015.pdf>. Acesso em: 19 nov. 2015.

LENCIONI, S. Linhas de pesquisa da pós-graduação em geografia. Mudanças, esquecimentos e emergência de (novos) temas. Revista da Anpege, (Associação Nacional de Pós-Graduação em Geografia). São Paulo, 2013. 
MORAES, A. C. R. Renovação da Geografia e filosofia da educação. In: OLIVEIRA, A. U. (Org.). Para onde vai o ensino de Geografia? São Paulo: Contexto, 1989.

PINHEIRO, A. C. O ensino de Geografia no Brasil. Goiânia: Editora Vieira, 2005.

MOREYRA, R. O discurso do avesso (Para a crítica da geografia que se ensino). Rio de Janeiro: Dois Pontos, 1987.

ROMANOWSKI, J. P.; ENS, R. T. As pesquisas denominadas do tipo "estado da arte” em educação. Diálogo Educ., Curitiba, v. 6, n. 19, p. 37-50, set./dez, 2006.

SILVA, J. B. da. A pesquisa e a produção geográfica. Revista da Anpege, São Paulo, v. 7, n. 1 número especial, p. 135-146, out. 2011.

SUERTEGARAY, D. M. A. A expansão da pós-graduação em geografia e a Anpege. Revista da Anpege, São Paulo, v. 1, n. 1, 2003.

VESENTINI, J. W. Para uma geografia crítica na escola. São Paulo: Ática, 1992.

. O ensino de geografia no século XXI. In: Caderno Prudentino de Geografia. n. 17. Presidente Prudente: AGB, jul. 1995.

ZANATTA, B. A. As referências teóricas da geografia escolar e sua presença na investigação sobre as práticas de ensino. In: EDUCATIVA, Goiânia, v. 13, n. 2, p. 285-305, jul./dez. 2010.

Lana de Souza Cavalcanti possui licenciatura em Geografia pela Universidade Federal de Goiás, mestrado em Educação pela mesma universidade, doutorado em Geografia pela Universidade de São Paulo, e pós-doutorado pela Universidad Complutense de Madrid. Atualmente, ela é professora titular na Universidade Federal de Goiás. 